Stannus, H. S. (1944). Brit. med. F. ii, 103, 140.

Stannus, H. S. (1945). Proc. R. Soc. Med. 38, 337.

Sydenstricker, V. P., Sebrell, W. H., Cleckley, H. M. \& Kruse, H. D. (1940). F. Amer. med. Ass. II4, 2437.

Trowell, H. C. \& Muwazi, E. M. K. (1945a). Trans. R. Soc. trop. Med. Hyg. 39, 229.

'Trowell, H. C. \& Muwazi, E. M. K. (1945b). Arch. Dis. Childh. 20, i 10.

Van Veen, A. G. (1942). Ann. Rev. Biochem. II, 391.

Waterlow, J. C. (1948). Spec. Rep. Ser. med. Res. Coun., Lond., no. 263.

Weiss (1873). Berl. klin. Wschr. p. 232 (quoted by Pillat).

Widdowson, E. M. \& McCance, R. A. (1943). Lancet, 244, 230.

Wolbach, S. B. \& Bessey, O. A. (1942). Physiol. Rev. 233.

\title{
A Photoelectric Spectrophotometer Suitable for the Measure- ment of Vitamin A by the Antimony-Trichloride Reaction
}

\author{
BY S. Y. THOMPSON \\ National Institute for Research in Dairying, University of Reading
}

(Received 29 Fanuary 1949)

The measurement by visual methods of the fleeting blue colour of vitamin $A$ in the antimony-trichloride reaction presents considerable difficulties which can be largely overcome by the use of photoelectric methods with corresponding increase in accuracy.

The photoelectric spectrophotometer now described was constructed in I94I when no comparable instrument of this type was commercially available here. It has been in continuous use in this laboratory ever since (Thompson, Kon \& Mawson, 1942; Kon, Mawson \& Thompson, I944; Mattick, Hiscox, Crossley, Lea, Findlay, Smith, Thompson, Kon \& Egdell, I945; Blaxter, Kon \& Thompson, I946; Braude, Kon \& Thompson, 1946; Ganguly, Kon \& Thompson, I947; Thompson, Ganguly \& Kon, I947; Braude, Henry, Kon \& Thompson, I947; Braude, Coates, Henry, Kon, Rowland, Thompson \& Walker, r947; Aschaffenburg, Bartlett, Kon, Terry, Thompson, Walker, Briggs \& Cotchin, I948; Thompson, Ganguly \& Kon, I949). Apart, however, from a brief mention at a meeting of the Biochemical Society (Thompson, 1942) no description of the apparatus has so far been published and for this reason it is now reported here.

\section{EXPERIMENTAL}

\section{General}

The instrument is generally applicable to absorption measurements in the visible spectrum. It is of the direct-reading type and uses a monochromator which, for photoelectric spectrophotometry, has many advantages. If the spectral band isolated is sufficiently narrow, the readings obtained are in terms of universally applicable absolute units, so that results can be expressed without reference to standard solutions or calibration curves. Further, the instrument can be used for identification of coloured substances by measurement of the shape of their absorption curves and of the position of the absorption maxima.

The direct reading, instead of the null-point, method was chosen, as the instrument 
was designed primarily for the measurement of the fleeting antimony-trichloride reaction for vitamin A. A single photocell connected to a galvanometer is used, and the light source is sufficiently stable to ensure no change in intensity during the substitution in the light beam of solvent and solution cells.

\section{Description of instrument}

The instrument is shown in $\mathrm{Pl}$. I as a top view photograph and, in diagrammatic plan, in Fig. I. For continuous radiation a 12 V. $60 \mathrm{~W}$. motor-car bulb $(A)$ is used. It derives a constant voltage from the $230 \mathrm{~V}$. mains a.c. supply through a constant

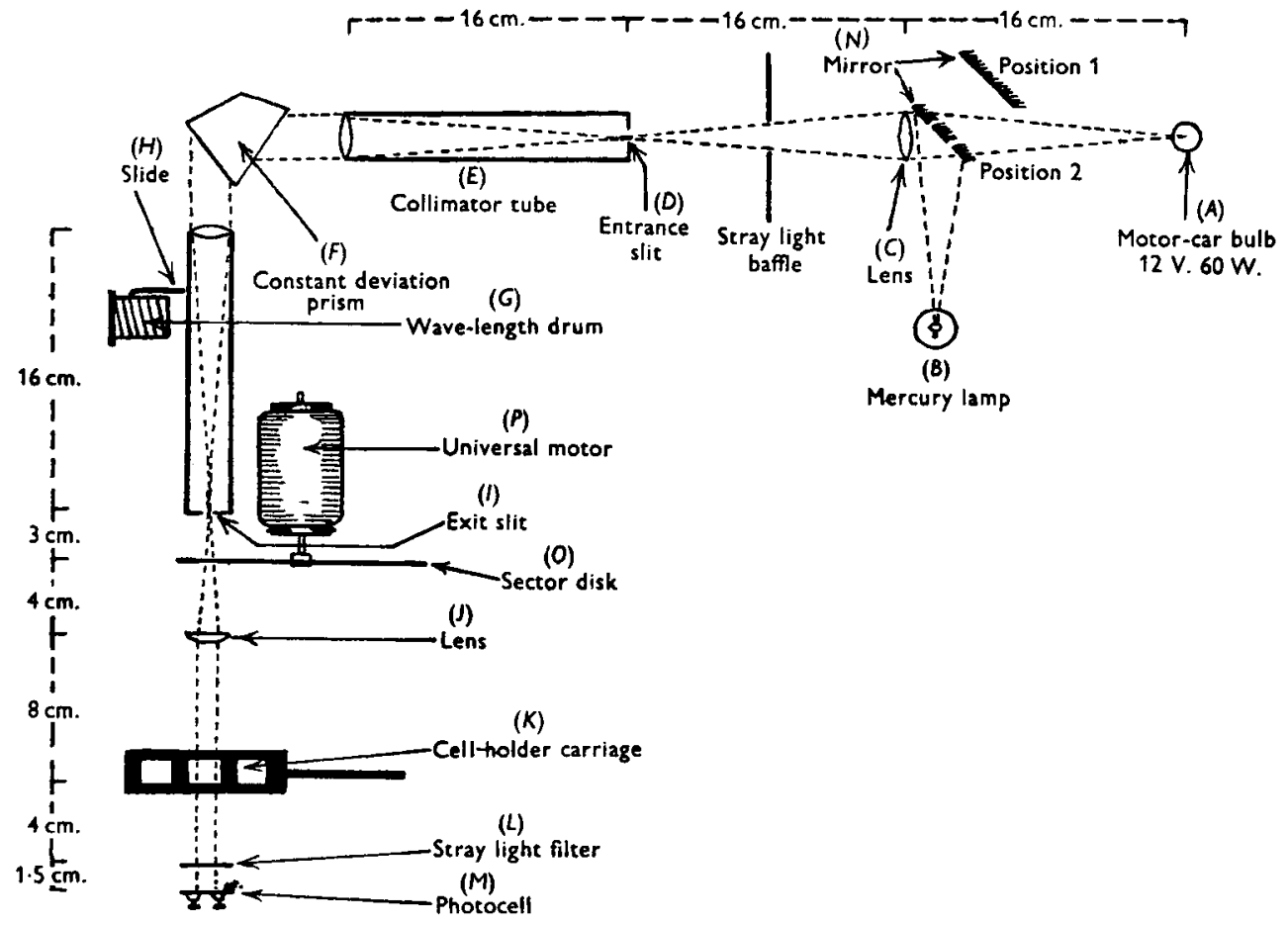

Fig. I. Diagrammatic plan of photoelectric spectrophotometer.

voltage and step-down transformer (not shown). For calibrating the spectrometer a I 25 W. Sieray (Siemens Electric Lamps and Supplies Ltd.) mercury-discharge lamp $(B)$ provides the lines characteristic of the mercury spectrum. An achromatic doublet convex lens $(C)$ focuses the light from either $(A)$ or $(B)$ on the entrance slit $(D)$ of the spectrometer. This lens produces a life-sized image of the filament which is larger than the entrance slit of the spectrometer. The beam then diverges in the collimator tube $(E)$ of the student-type spectrometer. The constant deviation prism $(F)$, built up of two $30^{\circ}$ and one $90^{\circ}$ prisms and made of the densest genuine heavy flint, is sufficiently large to make use of all the light available.

The prism table is rotated by a wave-length drum $(G)$ mounted on a length of 0.25 in. screwed rod with forty turns to the inch. The outer edge of the drum is marked 
S. Y. THOMPSON. Photollectric spectrophotometer for vitamin A

Plate I

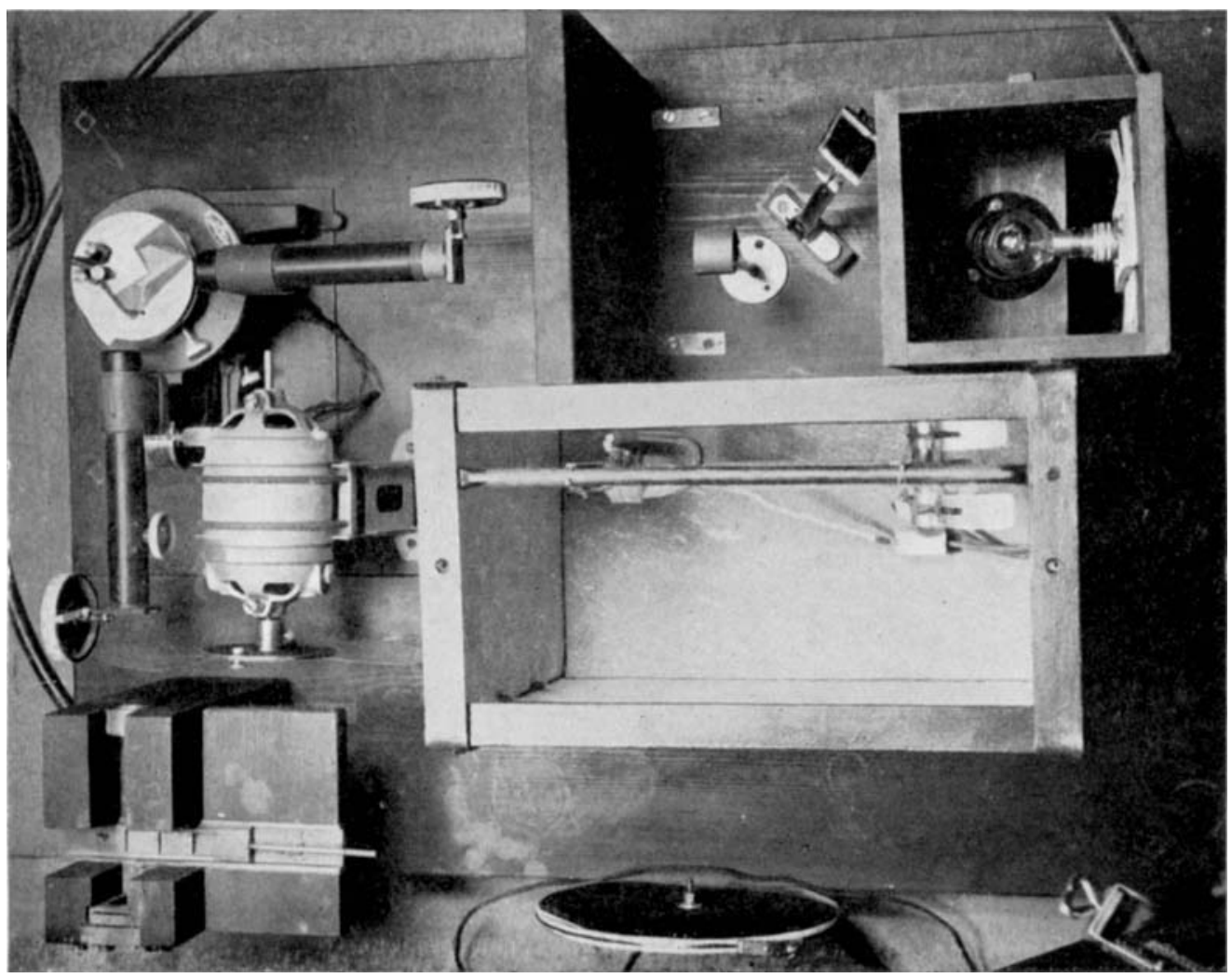

Top view photograph of instrument. A key to the components is given in Fig. I.

British Fournal of Nutrition, Vol. 3, No. I 
with 100 divisions and the slide $(H)$ is marked for each complete revolution of the drum. The eyepiece of the spectrometer is replaced by an exit slit $(I)$ similar to the entrance slit; both slits are fitted with drums calibrated in $\mathrm{mm}$. of aperture of the jaws. The light in the monochromatic beam from the exit slit is rendered nearly parallel by an achromatic plano-convex lens $(J)$, and next passes through the absorption cells held in the brass carriage $(K)$ and the appropriate stray light filter $(L)^{*}$, and finally reaches the barrier-layer photocell $(M)$ (Evans Electroselenium Ltd.) as a circular beam $c .1 \mathrm{~cm}$. in diameter. A series of five filters (Chance Bros. Ltd., nos. 2, 4, 5, 6, 7) is used.

To accommodate the small volume of liquid suitable for biochemical work, $U$-shaped fused absorption cells with a light path of $\mathrm{x} \mathrm{cm}$. requiring only $2 \mathrm{ml}$. of solution are used. Ogal cells, obtainable from The Tintometer Ltd., are suitable. Three of these cells can be placed in the carriage $(K)$ designed to allow location of each cell in the beam. Normally, two cells, one with the solvent alone, the other with the solution of the unknown, are used.

The Evans cells have a high response at the blue end of the spectrum and have stable and uniform characteristics. The current output from the photocell is taken to a Cambridge d'Arsonval galvanometer of $400 \Omega$. resistance, and sensitivity $5500 \mathrm{~mm} . / \mu \mathrm{A}$. at a scale-to-galvanometer distance of $5 \mathrm{~m}$. when critically damped by an $8000 \Omega$. resistance. This galvanometer has a period of $2 \mathrm{sec}$.

Two scales are used, one linear, suitable for transmission measurements, the other logarithmic, graduated in such a way that readings are made in terms of the extinction $E$ (Society of Public Analysts, I942), but to simplify the numerical aspects of the scale a proportionality factor is introduced.

\section{Spectrometer}

\section{Calibration of instrument}

Wave-length calibration. The mercury-vapour lamp $(B)$ is used as a source of emission lines. A microscope with a 2 in. objective is placed so that the jaws of the exit slit are in sharp focus; then, with the entrance slit wide open, the mirror $(N)$ is used to bring the radiation of the mercury lamp on to it. A mercury line is selected, and the entrance slit is narrowed till the line is as thin as possible. By rotating the wave-length drum the line is moved till its left-hand side coincides with the edge of the left-hand jaw of the slit, as seen in the eyepiece of the microscope. This is done in turn for each mercury line, and a curve is plotted expressing the drum readings in terms of wave-length.

Calibration of the slits for aperture. This is done with the same microscope fitted with an eyepiece containing a scale. With the entrance and exit slits calibrated in $\mathrm{mm}$. it is possible to determine the dispersion of the instrument and to plot the dispersion in $\mathrm{m} \mu . / \mathrm{mm}$. against wave-length; from this curve it is possible to calculate the spectral band at a chosen wave-length for a given opening of the slits. The value so obtained is only applicable for a line source; for continuous radiation, the spectral impurity is approximately twice that calculated for a line source (Hogness, Zscheile \& Sidwell, 1937).

* As a further precaution against stray light a black mask with a circular aperture slightly larger than the beam is placed directly in front of the photocell and the instrument is used in a dimly lit room. 


\section{Galvanometer}

The calibration of the galvanometer is carried out over the range of deflexion normally used by applying known voltages from a $2 \mathrm{~V}$. accumulator and potentiometer slide-wire.

\section{Relationship between the galvanometer deflexion and light intensity}

The relationship was originally checked by three methods: optical bench, the summation of a number of beams of equal intensity (Preston \& Cuckow, 1936), and the sector disk. The three methods gave identical results, but the sector-disk method was adopted for routine checking under working conditions of the whole instrument, as it was the most accurate and rapid. For this purpose six interchangeable sheet-iron sector disks $(O)$ (Fig. I), giving transmissions of $75,50,37.5,25,12.5$ and $5 \%$, may be used. The sectors are rotated by a universal motor $(P)$ in the beam of the spectrometer between the exit slit $(I)$ and the collimating lens $(J)$. Usually only a check with the $50 \%$ disk is necessary. As a further check on the calibration, a neutral glass filter previously calibrated throughout the visible spectrum by the National Physical Laboratory was tested at $620 \mathrm{~m} \mu$. and found to have an extinction of $\mathrm{I} .08$ instead of the N.P.L. value of 1.07 . In addition, to test the monochromaticity of the apparatus the extinction of an alcoholic solution of Victoria Blue was measured. Such a solution has an absorption maximum and curve very similar to those of the blue colour produced by the antimony-trichloride reaction for vitamin A. It was kindly supplied by Dr Mead of the British Drug Houses Ltd. who gave its $E_{1}^{1 \%} \mathrm{~cm}$. value at $618 \mathrm{~m} \mu$. as $\mathrm{I} \cdot \mathrm{Or}$. The value found was $\mathrm{I} \cdot 02$.

\section{General}

\section{Procedure for making absorption mesurements}

The wave-length setting is checked by observation of a mercury line, while the source of continuous radiation previously switched on is warming up. The desired wave-length is then selected and the appropriate stray-light filter placed in its holder. By placing the sector disk in the beam the light is prevented from reaching the photocell, and the position of the galvanometer pointer at rest is made to coincide with the infinity mark (zero transmission) on the scale. Next the absorption cell filled with solvent is placed in the beam which is now allowed to reach the photocell. The slits are then opened equally till the full-scale deflexion is obtained. A rapid check is then made with the $50 \%$ sector disk. The instrument is now ready for the actual measurement.

For stable solutions, such as those of carotene, the solution cell is placed in the beam and the galvanometer deflexion noted. The special procedure for vitamin $\mathrm{A}$ is described below.

\section{Measurement of vitamin $A$}

Substances containing only vitamin $A$. The measurement is carried out as follows. The solvent cell is placed in position in the beam, and the settings of the galvanometer for full-scale deflexion and for no deflexion are checked. Into the other cell $0.5 \mathrm{ml}$. of vitamin A solution in chloroform (or $n$-hexane) is pipetted and one drop of acetic 
anhydride (or four drops) are added; this cell is then placed in the beam, $2 \mathrm{ml}$. of antimony-trichloride reagent (British Drug Houses Ltd.) are rapidly added from the automatic delivery pipette of British Drug Houses Ltd. and the first stable galvanometer reading is taken. This is usually within $3-4 \mathrm{sec}$. of the beginning of mixing of reagent and solution. It will be noted that Moore's (1929) proportions of reagent to vitamin A solution are used. Under certain conditions it is necessary to use more acetic anhydride. Calibration curves must be prepared for each proportion of anhydride.

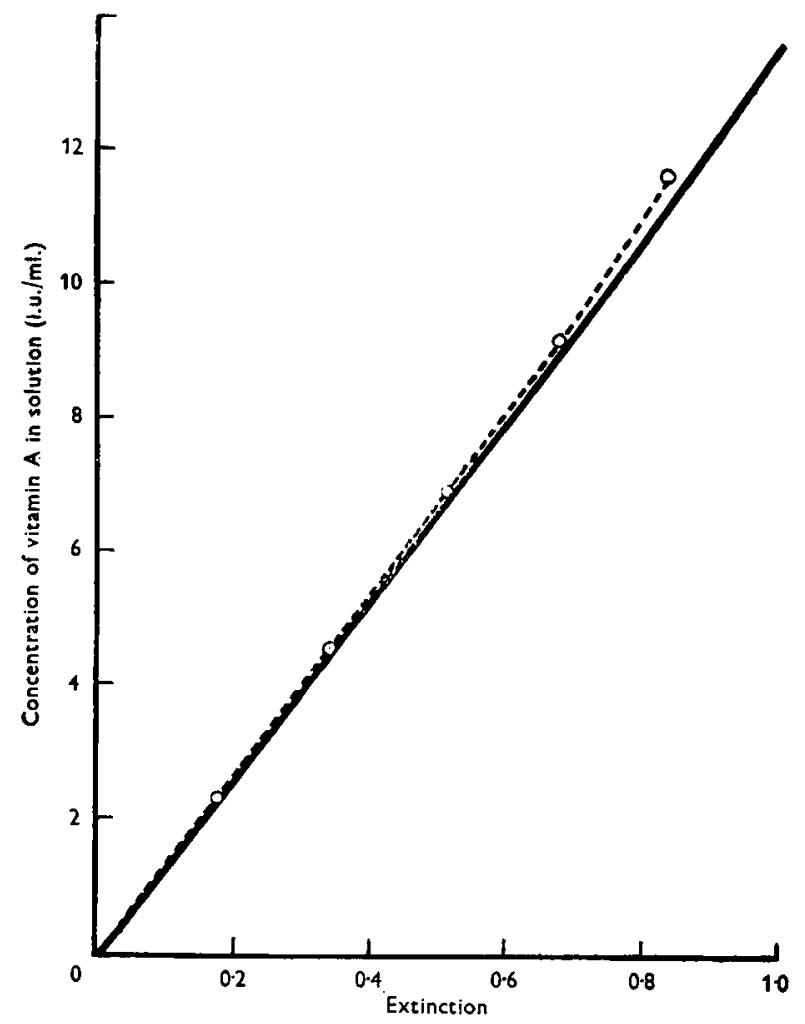

Fig. 2. Relationship between concentration of vitamin $A$ in chloroform and extinction at $620 \mathrm{~m} \mu$. in the antimony-trichloride reaction. Spectral impurity $8 \mathrm{~m} \mu$. $0--0$ values observed; straight line through origin and first point determined.

For the initial checking of the instrument, a distilled fish-liver oil concentrate of natural esters kindly supplied by Dr T. H. Mead of British Drug Houses Ltd. was used. Dr Mead, with a Hilger medium quartz spectrograph and a Bellingham and Stanley visual spectrometer, obtained for it the following characteristics: $E_{1 \mathrm{~cm}}^{1 \%}$ at $325 \mathrm{~m} \mu .=106 ; E_{1}^{1 \%}$. at $620 \mathrm{~m} \mu$. (antimony-trichloride reaction) $=324$. Values found by the method outlined above for $E_{1}^{1 \%}$ om. at $620 \mathrm{~m} \mu$. (spectral band $8 \mathrm{~m} \mu$.) varied from 316 to 324 . The potency of this oil in international units was taken as $106 \times 1600 \equiv 170,000$ i.u./g. Recent measurements of a similar concentrate by Dr Mead, Prof. Morton, who used a Beckman photoelectric spectrophotometer, and myself yielded, in all three laboratories, a value of 160,000 i.u./g. For a fish-liver oil two 
analyses in this laboratory gave values of 31,000 and 30,300 i.u./g. and Prof. Morton found 31,000 i.u. $/ \mathrm{g}$.

Tests with chloroform dilutions of fish-liver oil or crystalline vitamin A acetate or naphthoate covering the range for $E$ from $O \cdot I$ to $I \cdot 0$ (c. 2.2-22.2 i.u./ml.) showed that extinction values plotted against concentration deviated to the extent of $5 \%$ from the straight line drawn through the first point determined and the origin (Fig. 2). A suitable curve was therefore constructed from which the concentration of vitamin A in terms of international units could be read directly.

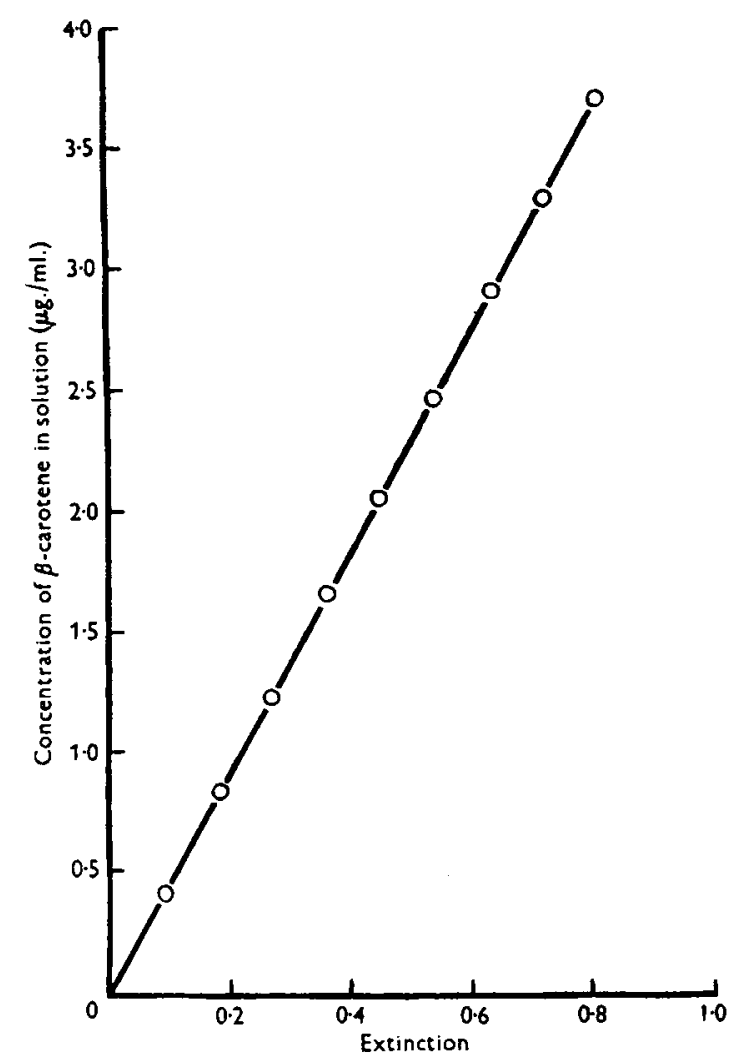

Fig. 3. Relationship between concentration of $\beta$-carotene in chloroform and extinction at $463 \mathrm{~m} \mu$. Spectral impurity $8 \mathrm{~m} \mu$.

Notevarp \& Weedon (1936), using a spectrometer, and Dann \& Evelyn (1938), using a photoelectric colorimeter, found that the intensity of the colour developed in the antimony-trichloride reaction is a linear function of the concentration of Vitamin A. On the other hand, Koehn \& Sherman (1940), using the same instrument as Dann \& Evelyn, were unable to confirm these findings.

Substances containing carotenoids in addition to vitamin $A$. Since carotenoids give a blue colour with antimony trichloride (for $\beta$-carotene $E_{1}^{1 \%}$. at $5^{85} \mathrm{~m} \mu .=420$ according to Gillam (I935)), a correction for this contribution of colour is necessary in the measurement of vitamin A. A series of solutions containing vitamin $A$ and 
$\beta$-carotene in different proportions was prepared, and measurements showed that within the range found in, for instance, butters, the scale reading for the blue colour due to carotene at $620 \mathrm{~m} \mu$. amounted to 0.02 of the scale reading for carotene in chloroform at $463 \mathrm{~m} \mu$., taken as described below. Measurements of vitamin $\mathrm{A}$ in substances in which carotenoids are present are therefore corrected in this way. Strictly speaking, the correction should vary according to the carotenoid, but in most cases, especially with butters, the carotenoids consist largely of $\beta$-carotene. In any case, with the narrow spectral band $(8 \mathrm{~m} \mu$.) of the instrument, the correction is much smaller than that necessitated by instruments using filters, and the use of only one correction factor cannot lead to any serious error.

\section{Measurement of carotenoids}

All carotenoids are measured at $463 \mathrm{~m} \mu$. when in chloroform and at $45 \mathrm{I} \mathrm{m} \mu$. when in $n$-hexane or light petroleum, that is, at the absorption maxima of $\beta$-carotene. In expressing their concentration it is assumed that their molar extinction coefficient $\epsilon$ is equal to that of $\beta$-carotene. The measurement itself is done as described above (p. 46). The relation between concentration and extinction is strictly linear (Fig. 3). For checking the instrument the sample of crystalline $\beta$-carotene described by Braude, Foot, Henry, Kon, Thompson \& Mead (194r) was used. The absorption of a series of dilutions in chloroform and in light petroleum (b.p. 40-60\% was measured with a spectral band of $8 \mathrm{~m} \mu$. The values obtained were $E_{1 \mathrm{~cm}}^{1 \%}$, at $463 \mathrm{~m} \mu$. in chloroform $=225 \circ ; E_{1}^{1 \%} \mathrm{~cm}$. at $45 \mathrm{I} \mathrm{m} \mu$. in light petroleum $=2360$.

\section{SUMMARY}

I. A detailed description is given of the setting up and calibration of a photoelectric spectrophotometer of the direct-reading type specifically designed for the measurement of the fleeting blue colour in the antimony-trichloride reaction for vitamin A, but generally applicable to absorption measurements in the visible spectrum.

2. With a spectral impurity of $8 \mathrm{~m} \mu$. the apparatus is suitable for the measurement of absorption curves of carotenoids.

I would like to acknowledge the help and advice given to me during the construction and calibration of the instrument by Mr J. S. Preston of the National Physical Laboratory, Dr T. B. Rymer of the University of Reading and Dr S. K. Kon of this Institute.

\section{REFERENCES}

Aschaffenburg, R., Bartlett, S., Kon, S. K., Terry, P., Thompson, S. Y., Walker, D. M., Briggs, C. \& Cotchin, E. (1948). Biochem. F. 42, xxx.

Blaxter, K. L., Kon, S. K. \& Thompson, S. Y. (1946). F. Dairy Res. 14, 225.

Braude, R., Coates, M. E., Henry, K. M., Kon, S. K., Rowland, S. J., Thompson, S. Y. \& Walker, D. M. (1947). Brit. F. Nutrit. I, 64 .

Braude, R., Foot, A. S., Henry, K. M., Kon, S. K., Thompson, S. Y. \& Mead, T. H. (1941). Biochem. F. 35, 693 .

Braude, R., Henry, K. M., Kon, S. K. \& Thompson, S. Y. (1947). Brit. F. Nutrit. 1, vi.

Braude, R., Kon, S. K. \& Thompson, S. Y. (1946). F. Dairy Res. r4, 414.

Dann, W. J. \& Evelyn, K. A. (1938). Biochem. F. 32, 1008.

N III I 
Ganguly, J., Kon, S. K. \& Thompson, S. Y. (r947). Brit. F. Nutrit. I, iii.

Gillam, A. E. (1935). Biochem. $\mathscr{7} .29$, I 831 .

Hogness, T. R., Zscheile, F. P. \& Sidwell, A. E. (1937). F. phys. Chem. 4r, 379.

Koehn, C. J. \& Sherman, W. C. (1940), F. biol. Chem. 132, 527.

Kon, S. K., Mawson, E. H. \& Thompson, S. Y. (1944). Nature, Lond., 154, 82.

Mattick, A. T. R., Hiscox, E. R., Crossley, E. L., Lea, C. H., Findlay, J. D., Smith, J. A. B., Thompson, S. Y., Kon, S. K. \& Egdell, J. W. (1945). F. Dairy Res. r4, I I6.

Moore, T. (1929). Biochem. F. 23, 1267.

Notevarp, O. \& Weedon, H. W. (1936). Biochem. F. 30, 1705.

Preston, J. S. \& Cuckow, F. W. (1936). Proc. R. phy's. Soc. Lond. 48, 869.

Society of Public Analysts, Publication Committee (1942). Analyst, 67, 164.

Thompson, S. Y. (1942). Chem. Eீ Ind. 6r, 170.

Thompson, S. Y., Ganguly, J. \& Kon, S. K. (1947). Brit. F. Nutrit. r, v.

Thompson, S. Y., Ganguly, J. \& Kon, S. K. (1949). Brit. F. Nutrit. 3, 5o.

Thompson, S. Y., Kon, S. K. \& Mawson, E. H. (1942). Biochem. F. 36, xvii.

\title{
The Conversion of $\beta$-Carotene to Vitamin $A$ in the Intestine*
}

\author{
By S. Y. THOMPSON, J. GANGULY AND S. K. KON \\ National Institute for Research in Dairying, University of Reading
}

(Received 29 Fanuary 1949)

When Moore (1930) first showed that vitamin A is formed from carotene in the animal body he assumed (Moore, 193I) that the conversion takes place in the liver, and this view was generally held until quite recently. It never explained satisfactorily why the blood of many mammals, including the rat, pig, sheep and goat, contains only traces of carotenoids or how carotene reaches the liver in these animals. A possible explanation is that it travels only through the portal vein to be at once removed by the liver and thus never reaches the general circulation, but Goodwin, Dewar \& Gregory (1946) found recently no carotene in blood samples from the portal vein of sheep and goats taken at intervals after the introduction of carotene into the abomasum, though vitamin A similarly given appeared in large quantities.

At about the same time Sexton, Mehl \& Deuel (1946) observed that carotene, introduced parenterally into vitamin A-deficient rats, accumulated in the liver without being converted into vitamin A or relieving the symptoms of deficiency. In commenting on these findings Sexton $e t$ al. said: 'One explanation of these phenomena would be that carotene is transformed into vitamin $\mathrm{A}$ in the rat before reaching the blood stream. A possible site for the transformation of carotene to vitamin A might be the intestinal wall.'

For some years now we have been working on the metabolism of carotenoids and of vitamin A in rats and in pigs, and the observations of Goodwin et al. (1946) and of Sexton et. al. (1946) underlined our growing doubts about the part played by the liver in the formation of vitamin $A$. The work now described, of which, so far, only a preliminary note has been published (Thompson, Ganguly \& Kon, 1947), fully supports

* Read in part before The Nutrition Society on 31 May 1947 (Thompson, Ganguly \& Kon, 1947). 